DOI: http://doi.org/10.46667/renbio.v14i1.553

\title{
CONCEPÇÕES DE PROFESSORES NA FORMAÇÃO INICIAL DE CIÊNCIAS NATURAIS PARA A EDUCAÇÃ O EM SEXUALIDADE E AFETIVIDADE
}

\author{
CONCEPTIONS OF TEACHERS IN INITIAL TRAINING OF NATURAL \\ SCIENCES TOWARDS EDUCATION IN SEXUALITY AND AFFECTIVITY \\ CONCEPCIONES DE MAESTROS Y MAESTRAS EN FORMACIÓN \\ INICIAL DE CIENCIAS NATURALES HACIA LA EDUCACIÓN \\ EN SEXUALIDAD Y AFECTIVIDAD
}

\author{
Jonathan Andrés Mosquera ${ }^{1}$; José Joaquín García García ${ }^{2}$
}

\begin{abstract}
Resumo
Este estudo faz parte de uma pesquisa de doutorado que caracteriza as concepções de professores em formação em ciências naturais para a Educação Afetivo-Sexual. Assim, o estudo é qualitativo e foi elaborado um questionário com 22 questões em torno do tema de interesse. Esse instrumento foi aplicado a 50 professores participantes, e suas respostas foram sistematizadas em categorias emergentes da análise de conteúdo. Os resultados são apresentados em torno das categorias: Natureza da Sexualidade, Dimensão Afetiva, Diversidade Sexual, e Objetivos de Ensino. Desta forma, destaca-se o interesse dos professores em abordar as questões da sexualidade humana a partir de posturas biopsicossociais, estabelecendo processos de formação continuada que contribuam para suas práticas educacionais.
\end{abstract}

Palavras-chave: Sexualidade; Concepções; Formação dos professores; Ensino das Ciências.

\begin{abstract}
This study is part of a doctoral research that characterizes the conceptions of teachers in training in natural sciences towards Affective-Sexual Education. Thus, the study is qualitative and has been designed a questionnaire with 22 questions has been around the topic of interest. This instrument was applied to 50 participating teachers, and their responses were systematized into emerging categories from the content analysis. The findings are presented around the categories: Nature of Sexuality, Affective Dimension, Sexual Diversity and Teaching Purposes. In this way, the interest of teachers in addressing human sexuality issues from biopsychosocial positions is highlighted and establishing continuous training processes contributing to their educational practices.
\end{abstract}

Keywords: Sexuality; Conceptions; Teacher Training; Science Education.

\footnotetext{
${ }^{1}$ Doutorando em Educação em Ciências Naturais da Universidade de Antioquia (Medellín, Colômbia). Docente da Universidade Surcolombiana (Neiva, Colômbia). Bolsista do Bicentenário pelo Ministério de Ciência, Tecnologia e Inovação (Min Ciências). E-mail: jonathan.mosquera@usco.edu.co.

${ }^{2}$ Doutor em Didática das Ciências - Universidade de Granada. Docente Titular de Tempo Completo da Faculdade de Educação da Universidade de Antioquia (Medellín, Colômbia). E-mail: joaquin.garcia@udea.edu.co.
} 


\section{Resumen}

Este estudio hace parte de una investigación doctoral que caracteriza las concepciones del profesorado en formación en ciencias naturales hacia la Educación Afectivo-Sexual. Así, el estudio es cualitativo y fue diseñado un cuestionario con 22 interrogantes en torno a la temática de interés. Este instrumento fue aplicado a 50 docentes participantes, y sus respuestas fueron sistematizadas en categorías emergentes desde el análisis de contenido. Se presentan los hallazgos en torno a las categorías: Naturaleza Sexualidad, Dimensión Afectiva, Diversidad Sexual y Finalidades de Enseñanza. De esta manera, se destaca el interés del profesorado por abordar los asuntos de la sexualidad humana desde posturas biopsicosociales, y establecer procesos de formación continuada contribuyendo a sus prácticas educativas.

Palabras clave: Sexualidad; Concepciones; Formación del Profesorado; Educación en Ciencias.

***

\section{Introdução}

A educação sexual na Colômbia foi marcada pelo reconhecimento da sexualidade como uma questão essencial na formação humana. Este enfoque dado à Educação Sexual na Colômbia está relacionado com o desenvolvimento de políticas em torno da classificação da violência em estabelecimentos de ensino e com o desenho de rotas de acompanhamento escolar. Ou seja, a sexualidade a partir da normatividade é reconhecida como uma questão que permeia as diferentes etapas e esferas do desenvolvimento humano. Essa abordagem normativa na Colômbia foi registrada desde a reforma da Constituição Política de 1991, nesta, não só os direitos humanos e civis são reconhecidos para os colombianos, mas também são abordados aspectos do desenvolvimento humano, reconhecendo a sexualidade como um assunto pessoal e coletivo. Da mesma forma, na Lei Geral de Educação de 1994, afirma-se que o objetivo da Educação Sexual na Colômbia é promover e favorecer em todos os alunos uma formação rica em valores, sentimentos, conceitos e comportamentos para o desenvolvimento da responsabilidade e da autonomia. Esta definição parte-se do entendimento de que a sexualidade é inerente ao comportamento humano, e para isso a base da Educação Sexual deve ser o afeto e a igualdade entre as pessoas.

Da mesma forma, na Colômbia foi criada em 2013 a Lei 1620, que criou o Sistema Nacional de Convivência e Capacitação Escolar para o Exercício dos Direitos Humanos, Sexuais e Reprodutivos e Prevenção e Mitigação da Violência Escolar. Com esta Lei, de novo se fala no país da importância da Educação Sexual nas Instituições de Ensino é ratificada em caráter obrigatório. Neste caso, a rota de apoio escolar foi definida de forma a garantir a convivência escolar saudável e o desenvolvimento humano livre. Tal desenvolvimento é normativamente reconhecido como o conjunto de ações concretas que favorecem a interação social de meninos, meninas, adolescentes e jovens. Para isso, o ser humano faz uso pleno, alegre e responsável de sua sexualidade e promove um relacionamento saudável com o outro.

Apesar das orientações anteriores e das reflexões e estratégias que de uma forma ou de outra se promovem nos cenários formais e informais de formação em torno da sexualidade humana, esta questão social continua sujeita às concepções pessoais de cada aluno, às crenças culturais que se tecem na família e na sociedade, e às práticas de sala de aula onde participam 
DOI: http://doi.org/10.46667/renbio.v14i1.553

os sentimentos dos professores (CEDEÑO et al., 2017). Assim, reconhece-se que a Educação Sexual no país tem se desenvolvido a partir de abordagens com vieses e nuances descontextualizadas que, em alguns casos, acabam favorecendo as estatísticas de curto prazo, mas não transformam as práticas de sexualidade dos cidadãos. Em outras palavras, a sexualidade tem sido abordada em diferentes cenários de forma formal e informal, por uma questão de controle, em que a regulação normativa é a melhor forma e a forma certa de ser livre e feliz. Nessa felicidade, são recolhidas posturas comportamentais e utilizada a dignidade humana como critério do direito à convivência, deixando de lado a perspectiva do dever. Isso significa que falsos problemas têm se materializado em torno da importância da educação para a sexualidade e da relevância na vida do ser humano (MARINA, 2002). Essa realidade pode ser observada nos diferentes Modelos de Educação Sexual. Entre eles, estão aqueles voltados para as características biológicas de homens e mulheres, condicionando suas ações a vieses ideológicos e tradições moralistas, em que as práticas sexuais anteriores ao casamento são proibidas, e a possibilidade de pensar e expressar opiniões sem supervisão conjugal. Da mesma forma, passou por modelos clínicos (LAMEIRAS et al., 2016), em que prevaleceu o uso de linguagens técnicas que além de se desvincularem do contexto, se desvinculam das realidades pessoais. Esses modelos de cortes preventivos, embora tenham impactado no controle de questões como o parto e as práticas sexuais de risco (gravidez precoce, doenças sexualmente transmissíveis, aborto), estavam desconectados da realidade afetiva do ser humano (FALLAS, 2009; MOSQUERA; GARCÍA, 2020). Então, são modelos que partem da natureza humana construída como organismo biológico, esquecendo seu componente afetivo e cultural.

Além do exposto, é necessário reconhecer algumas questões teóricas que nos permitem pensar a educação sexual em uma perspectiva mais ampla, ou como tem sido chamada aqui a partir de uma abordagem biopsicossocial, onde além dos elementos biológicos, os fatores afetivos, social e cultural.

\subsection{Aspecto Comportamental-Biológico}

O problema da afetividade, emoções e sentimentos é que são elementos essenciais da cultura humana. Assim, na sexualidade como fenômeno cultural, o comportamento sexual não está relacionado apenas ao aspecto biológico (sexo), mas também é interpretado a partir da construção social, das redes neurais que determinam as expressões mentais (sentimentos), respostas a estímulos internos e externos (emoções) e as valências desse sentimento (afetos). Esse fator neurobiológico condiciona os processos comportamentais e afeta a consciência e sua subjetividade, e determina a tomada de decisões em relação à sexualidade. Além disso, a sexualidade engloba cenários, que incluem a apropriação de si, o uso de prazeres e a vontade de saber se relacionar em comunidade (FOUCAULT, 2003).

$\mathrm{Na}$ evolução das espécies, foi reconhecido que a dinâmica das mudanças, algumas sucessivas e outras espontâneas, mas nunca condicionadas por um período de tempo definido, está intimamente relacionada com a homeostase. Para Damásio (2018), a homeostase se refere ao conjunto fundamental de processos encontrados no próprio cerne da vida, desde seu início na bioquímica primitiva até o presente. Esse interesse na sobrevivência e adaptação na 
DOI: http://doi.org/10.46667/renbio.v14i1.553

sobrevivência foi referenciado na filosofia por Spinoza como "Conatus", aquela força que pode ser apreciada em uma escala microscópica em todas as células vivas e que pode ser projetada em uma escala macroscópica em toda a natureza (LENOIR, 2019). Pois, sem ter consciência disso, todos os organismos geram diferentes ações que se orientam para a persistência no futuro. É justamente nessas interações específicas que se baseiam processos como a educação, o ensino e a aprendizagem, e se gera a cultura que possibilita o desenvolvimento da mente no ser humano (DAMASIO, 2018).

Dessa forma, pode-se estabelecer que os sentimentos são aquelas experiências mentais e conscientes que o ser humano tem. Se o processo não fosse consciente, não seria possível ter um conhecimento direto sobre os sentimentos (DAMASIO, 2018). No entanto, esses tipos de experiências mentais diferem dos outros em aspectos como seu conteúdo e sua valência. Assim, esse conteúdo contém as representações do interior ao nível dos órgãos e seus processos, as reações homeostáticas, as interações de resposta a estímulos e as condições em que as imagens do interior são processadas. Por sua vez, a valência qualifica inevitavelmente o estado do corpo, como bom ou mau. De forma que quando vivenciamos estados que promovem a sobrevivência, aludem a "Connatus", a valência é positiva e é classificada como agradável (LENOIR, 2019). Do contrário, aconteceria, se a experiência não fosse favorável, a valência é negativa e é classificada como desagradável.

Além disso, a afetividade é reconhecida como o acúmulo de reações químicas e interações com os diferentes substratos sobre os quais a mente é construída e os diferentes sinais de estado, tanto internos quanto externos ao corpo (DAMASIO, 2003). Então, o afeto torna-se epistemologicamente uma construção social que engloba todas as respostas homeostáticas do ser humano. Estes incluem emoções (corpo), sentimentos espontâneos ou homeostáticos (mente) e seus mecanismos neurobiológicos, em virtude de buscarem transformar ações, experiências e memórias em reações conscientes (que requerem subjetividade e experiência integrada), digamos, sentimentos.

Isso significa que o valor dos sentimentos em particular se traduz em afeto. Este último está relacionado à valência, que é entendida como uma qualidade intrínseca da experiência, e que pode ser agradável ou desagradável. Em outras palavras, a valência é o elemento que define o sentimento e, portanto, o afeto. Assim, uma questão de natureza pessoal e coletiva, como a sexualidade, é construída a partir de vários afetos e sua transformação em sentimentos de diferentes valências neurobiológicas que afetam as ações conscientes e sensíveis do ser humano.

\subsection{Educação em Saúde (ES)}

Para abordar a sexualidade, é preciso falar em Educação em Saúde (ES) e Dimensão Afetivo-Sexual, termos propostos por Valentín Gavidia e seu grupo de pesquisa. Para este grupo acadêmico, a saúde é uma questão de importância social, que no campo da educação em ciências está ligada ao pensamento crítico. Isso visto que a saúde é um fenômeno cultural não apenas sujeito a concepções e realidades, mas também, por ter manifestações tão variadas, deve 
DOI: http://doi.org/10.46667/renbio.v14i1.553

estar voltada para sua articulação na escola, não só a partir das ciências, mas também de forma diferenciada e integral na formação humana. Desta forma, para o caso desta pesquisa, reconhece-se que Educação em Saúde é "aprender a cuidar de si, aprender a cuidar dos outros e aprender a cuidar do meio ambiente" (ALIAGA et al., 2016, p. 50). Esta definição se adapta muito bem a todas as dimensões da formação humana, pessoal, relacional ou social e ambiental (cuidado pessoal e coletivo).

Da mesma forma, a Organização Mundial da Saúde - OMS tem falado de "Alfabetização em Saúde" e a define como "as habilidades sociais e cognitivas que determinam o nível de motivação e a capacidade de uma pessoa acessar, compreender e usar as informações de uma forma que permita você deve promover e manter uma boa saúde" (1998, p. 120). Essa definição se soma à ideia de reconhecer a ES como um processo que, embora social, diz respeito à pessoa e à gestão que ela dá às ferramentas que recebe durante sua formação. Assim, espera-se que o sujeito, imerso em um processo de treinamento, consiga manter uma boa saúde física e emocional tanto a nível pessoal como comunitário.

\section{3 A construção da dimensão afetivo-sexual de professores de ciências}

A formação dos professores de ciências, suas crenças e atitudes, estão intimamente relacionadas às práticas e discursos que os professores estabelecem em sala de aula em torno da sexualidade (PLAZA, 2015). Para Plaza, os professores de ciências têm várias crenças sobre sexualidade e questões de gênero. Segundo essa autora, as crenças e concepções são um componente central do Conhecimento Profissional e, no caso da Educação Sexual, são tecidas a partir do currículo escolar oculto em ciências. Dessa forma, pode-se estabelecer que durante a ação docente, os professores se apropriam de estratégias de reflexão metacognitiva que lhes permitem explicitar suas crenças e com isso afetam afetivamente as ações e atitudes dos alunos. No entanto, até o momento são poucos os estudos que revisaram os processos de reflexão dos professores de ciências e como as crenças por eles assumidas permitem a construção de conceitos e práticas para abordar o fenômeno da sexualidade em sala de aula.

Por outro lado, García-Vásquez et al., (2012) e Ocampo et al., (2016) afirmam que, as questões que se relacionam com a sexualidade humana exigem que os professores tenham maior controle sobre os conteúdos para abordar e um ensino eficaz estratégias de acordo com as particularidades de cada contexto. Por isso, é impossível parar de pensar na incidência das concepções e crenças que os professores têm sobre o fenômeno da sexualidade, tanto a partir da própria experiência de sentir-se e estar bem, quanto das relações que constroem na sociedade. Assim, é necessário que os professores se sintam bem com sua sexualidade, para que possam abordar os conteúdos desse eixo de formação em suas salas de aula (GARCÍA-VÁSQUEZ et al., 2012). Esses autores apontam que esse fator é essencial na Educação Sexual, uma vez que, estando o professor bem, impede que suas crenças se apropriem do cenário educacional e gerem tensões na aprendizagem do corpo discente. Esses achados estão relacionados aos relatos de Borrachero (2015), afirmando que a carga emocional dos professores de ciências é um poderoso agente de mudança conceitual e comportamental em crianças e adolescentes. Da mesma forma, 
DOI: http://doi.org/10.46667/renbio.v14i1.553

é reconhecido que os professores de ciências apresentam uma atitude vergonhosa quando devem responder às perguntas dos alunos sobre sexo, genitalidade, desenvolvimento humano e reprodução (OCAMPO, 2016). Essas atitudes e emoções vergonhosas dos professores surgem das crenças pessoais e sob as quais foram formados sobre a sexualidade (MORAWICKI et al., 2011).

Assim, considera-se importante que as abordagens educacionais prevaleçam nos programas de formação de professores e que reconheçam os obstáculos e oportunidades que cercam as crenças dos professores e das professoras. $\mathrm{O}$ reconhecimento de crenças permite compreender as emoções, julgamentos, intenções, necessidades e interesses que o professor possui e sua vinculação às práticas pedagógicas. Segundo Sordo (2017), ao reconstruir o pensamento e a ação do professor, ela é alcançada reflexivamente, despertando uma consciência sobre as ações pessoais e coletivas. Além disso, é favorecida uma educação sensível e afetiva, onde os obstáculos são reconhecidos, superados e transcendidos no ensino e aprendizagem de questões humanas complexas como a sexualidade.

Por tudo isso, é reconhecida a importância de uma formação sensível e humana que contribua para a conquista da felicidade (GARCÍA, 2018) diante de fenômenos como a sexualidade. Da mesma forma, essa formação é transversal ao currículo e articulada a partir de diferentes áreas do conhecimento no âmbito de um processo de Educação para a Saúde (GAVIDIA, 2016). Além disso, considera-se imprescindível a formação adequada, pertinente, reflexiva e sensível dos professores em torno das reais questões da sexualidade (PLAZA, 2015).

Desse modo, é realizada uma investigação com professores de ciências naturais em formação inicial, a fim de caracterizar suas concepções, atitudes e práticas em torno das questões da sexualidade humana e seu vínculo com o reconhecimento da afetividade como elemento formativo. Essa perspectiva é construída a partir da definição de uma Dimensão Afetivo-Sexual no âmbito da Educação em Saúde, e como seu reconhecimento nas aulas de ciências contribui para o desenvolvimento de didáticas alternativas para ensinar e aprender sobre sexualidade.

\section{Procedimentos Metodológicos}

Este estudo é de natureza qualitativa, onde a técnica de análise de conteúdo (BARDÍN, 1977) tem sido utilizada para construir um sistema de categorias e subcategorias que têm permitido agrupar as concepções dos professores participantes em relação à Dimensão AfetivoSexual nas tendências de pensamento. Para tanto, foi elaborado um questionário com 22 questões abertas em torno de eixos teóricos como a natureza da sexualidade; a relação da sexualidade com sentimentos e emoções; possíveis práticas em educação sexual; e a incidência de questões como pornografia, promiscuidade, sexo comercial e redes sociais na construção da sexualidade. Esse questionário foi validado por pesquisadores com ampla experiência na área temática e na formação de professores de ciências na América Latina. Dessa forma, foram 
DOI: http://doi.org/10.46667/renbio.v14i1.553

estabelecidas 21 Categorias, em cada uma delas foram atribuídas pontuações às subcategorias em virtude da sua aproximação a um nível de conhecimento ideal ou de referência. A Tabela 1 apresenta as categorias que são objeto de análise nesta escrita sobre as concepções de professores em formação inicial.

Tabela 1. Categorias de análise para concepções de professores

\begin{tabular}{|c|c|c|c|}
\hline Pergunta & Categoria & Subcategoria & Valoração \\
\hline \multirow{4}{*}{$\begin{array}{l}\text { Como você define a } \\
\text { sexualidade? }\end{array}$} & \multirow{4}{*}{$\begin{array}{l}\text { Natureza da } \\
\text { Sexualidade }\end{array}$} & Aspecto Biológico & 1 \\
\hline & & Questão Psicológica & 2 \\
\hline & & $\begin{array}{c}\text { Expression } \\
\text { Comportamental }\end{array}$ & 3 \\
\hline & & Construção Cultural & 4 \\
\hline \multirow{4}{*}{$\begin{array}{c}\text { Você acha que o } \\
\text { estudo das emoções } \\
\text { e sentimentos } \\
\text { poderia fazer parte } \\
\text { da Educação Sexual? } \\
\text { Por quê? }\end{array}$} & \multirow[t]{4}{*}{ Dimensão Afetiva } & $\begin{array}{c}\text { Não Sabe / Não } \\
\text { Responde }\end{array}$ & 1 \\
\hline & & $\begin{array}{c}\text { Campos } \\
\text { Independentes }\end{array}$ & 1 \\
\hline & & $\begin{array}{c}\text { Desenvolvimento } \\
\text { Pessoal }\end{array}$ & 2 \\
\hline & & $\begin{array}{c}\text { Desenvolvimento } \\
\text { Biopsicossocial }\end{array}$ & 3 \\
\hline \multirow{5}{*}{$\begin{array}{l}\text { A partir de sua } \\
\text { experiência pessoal e } \\
\text { formativa, até que } \\
\text { ponto as questões } \\
\text { relacionadas à } \\
\text { diversidade sexual } \\
\text { teriam espaço nas } \\
\text { aulas de ciências } \\
\text { naturais? }\end{array}$} & \multirow[t]{5}{*}{ Diversidade Sexual } & $\begin{array}{l}\text { Não Sabe / Não } \\
\text { Responde }\end{array}$ & 1 \\
\hline & & Informações Gerais & 2 \\
\hline & & $\begin{array}{c}\text { Reprodução } \\
\text { Biológica } \\
\end{array}$ & 2 \\
\hline & & $\begin{array}{l}\text { Reconhecimento da } \\
\text { Diversidade }\end{array}$ & 3 \\
\hline & & $\begin{array}{l}\text { Formação Humana } \\
\text { Integral }\end{array}$ & 4 \\
\hline \multirow{6}{*}{$\begin{array}{l}\text { Com base em sua } \\
\text { experiência e seu } \\
\text { treinamento como } \\
\text { futuro professor, que } \\
\text { propósitos você } \\
\text { levaria em } \\
\text { consideração para a } \\
\text { Educação Sexual? }\end{array}$} & \multirow[t]{6}{*}{ Propósitos de Ensino } & $\begin{array}{c}\text { Não Sabe / Não } \\
\text { Responde }\end{array}$ & 1 \\
\hline & & $\begin{array}{c}\text { Conhecimentos } \\
\text { Científicos }\end{array}$ & 2 \\
\hline & & $\begin{array}{l}\text { Promoção e } \\
\text { Prevenção }\end{array}$ & 2 \\
\hline & & $\begin{array}{c}\text { Componente } \\
\text { Atitudinal } \\
\end{array}$ & 3 \\
\hline & & $\begin{array}{l}\text { Inclusão da } \\
\text { Diversidade } \\
\end{array}$ & 3 \\
\hline & & $\begin{array}{c}\text { Formação Integral e } \\
\text { Cultural }\end{array}$ & 4 \\
\hline
\end{tabular}

Fonte: Autores 
DOI: http://doi.org/10.46667/renbio.v14i1.553

A população participante foi composta por 50 professores em formação inicial do Bacharelado em Ensino das Ciências Naturais e Educação Ambiental da Universidade Surcolombiana, que cursavam a disciplina de Didática das Ciências no semestre 2020-2. Da mesma forma, a população estava distribuída em 23 professores do sexo biológico masculino e 27 do sexo biológico feminino. Nessa distribuição, 92\% da população afirmou ter orientação heterossexual, $6 \%$ relatou orientação bissexual e o $2 \%$ restante são homossexuais. Em relação à faixa etária dos participantes, esta corresponde a um mínimo de 20 anos e um máximo de 33 anos. Em cada um dos casos, foi assinado o respectivo consentimento informado, e a participação voluntária dos professores em formação foi registrada por meio de um questionário no Google-Forms.

\section{Resultados e discussão}

Para o desenvolvimento desta secção, são apresentadas cada uma das categorias analisadas com as respectivas frequências e é feita uma análise dos referidos resultados a partir dos postulados da Educação Afetivo-Sexual.

\subsection{A definição de sexualidade que os professores em formação em ciências têm}

Nessa primeira categoria, fica evidente que as concepções sobre o conceito de sexualidade defendidas por professores em formação em ciências naturais caracterizam-se por tendências reducionistas de pensamento. Assim, 21 destes professores (42\%) consideram que a sexualidade é um “Aspecto Biológico” da espécie humana. Em outras palavras, a maioria desses professores concebe o fenômeno da sexualidade como uma questão de interesse ligada a fatores reprodutivos e genéticos das ciências naturais, e que se constrói a partir dos postulados da prevenção e do controle da natalidade. Da mesma forma, as concepções dos professores participantes sobre a sexualidade podem ser reconhecidas como uma "Questão Psicológica" (12 professores, 24\%), ou um conjunto de características que levam à "Expressão Comportamental" (9 professores, 18\%) no ser humano. Como pode ser observado na Figura 1, a tendência do pensamento minoritário ou subcategoria com menor frequência é a "Construção Cultural" com as respostas de 8 professores $(16 \%)$.

Figura 1: Frequências da Categoria da Natureza da Sexualidade

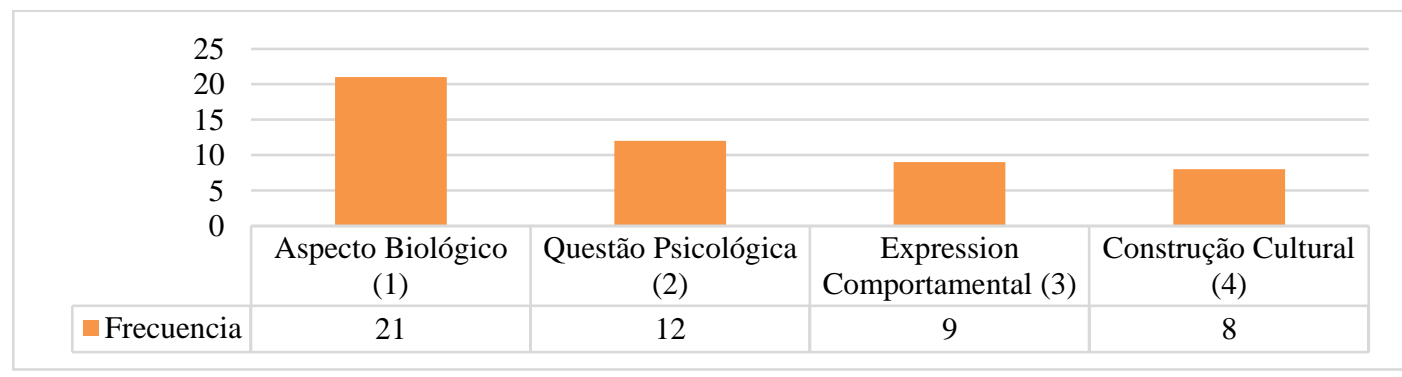

Fonte: Autores 
DOI: http://doi.org/10.46667/renbio.v14i1.553

A seguir, são apresentadas algumas evidências textuais das respostas dos professores em formação à questão desta categoria.

DF11.C1.P1 [Referindo-se à definição de Sexualidade como um Aspecto Biológico] "Como o que identifica a pessoa humana em sua essência e esplendor, conferindo-lhe características físicas e psicológicas de cada sexo".

DF22.C1.P1 [Referindo-se à definição de Sexualidade como uma Questão Psicológica] "é como uma troca de informações erógenas e agradáveis, entre duas pessoas, que se amam ou se atraem fisicamente, psicologicamente ou carnalmente".

DF1.C1.P1 [Referindo-se à definição de Sexualidade como Construção Cultural] "É tudo o que identifica o ser humano em termos de gênero, emoções, orientação sexual, comportamentos psicológicos, aspectos físicos e relacionamento sexual".

Conforme mostrado na Figura 1, as concepções dos professores participantes foram construídas a partir de uma perspectiva de controle, patologia ou prevenção, onde emoções como o medo tomam conta de seus discursos tanto ao pensar a sexualidade quanto ao buscar o seu ensino. Este tipo de concepções no corpo docente se enquadra num modelo de análise de risco da sexualidade (AGUD et al., 2016), talvez por terem aprendido e evocado experiências tradicionalistas descontextualizadas sob um Modelo de Risco e Prevenção. Então, os professores de ciências constroem concepções, atitudes e práticas sobre a sexualidade, a partir de abordagens voltadas para as consequências negativas das práticas sexuais, especialmente aquelas que podem levar às DST (Doenças Sexualmente Transmissíveis) e à gravidez precoce. Esses tipos de descobertas também foram relatados no trabalho de Plaza (2015). Este autor afirma que as concepções que os professores de ciências constroem sobre a sexualidade se enquadram em um modelo de risco ou preventivo, onde prevalece uma visão "biomédica", visão que em muitos contextos latino-americanos tem se fortalecido em contextos de formação inicial.

Por outro lado, o fato de os professores em uma porcentagem muito menor reconhecerem a sexualidade como conformada por elementos psicológicos, comportamentais e culturais, mostra como os professores ainda mantêm a perspectiva epistemológica típica da modernidade que com sua postura logocêntrica separa a mente, do corpo, do sentimento e da cultura, deixando-os sem possibilidades de interação entre eles (GARCÍA, 2020).

Este resultado mostra a necessidade de articular cenários de formação inicial para professores de ciências, que não só promovam a aprendizagem de conceitos científicos, mas também contribuam para o reconhecimento do pensamento, sentimento e ação dos professores em relação a questões de interesse sociocientífico como a sexualidade. como já foi reconhecido por outros estudos (AMÓRTEGUI, MOSQUERA, 2018; FALLAS, 2009; TALAVERA et al., 2018). Da mesma forma, esses resultados tornam-se importantes porque, segundo Plaza (2015), as crenças e atitudes dos professores de ciências são agentes fundamentais na formação em 
DOI: http://doi.org/10.46667/renbio.v14i1.553

sexualidade das novas gerações. Além disso, os resultados são relevantes porque a construção do fenômeno cultural da sexualidade é determinada além das questões biológicas por fatores sociais, que interagem na tomada de decisão de cada pessoa e fornecem elementos para seu comportamento afetivo-sexual (LAMEIRAS et al., 2016).

Nesta perspectiva, é necessário advogar pelo estabelecimento de uma Educação Sexual orientada sob Modelos Biográficos onde importe não só a componente biológica, mas também a afetiva e comunitária, e onde a pessoa seja reconhecida de forma integral como sujeito de direitos. e atribuições (LEÓN et al., 2013).

3.2 Ligando emoções e sentimentos ao estudo da sexualidade do ponto de vista dos professores de ciências

Quando os professores participantes da formação foram questionados sobre a possibilidade de vincular emoções e sentimentos no estudo da sexualidade humana, a maioria (29 professores, 58\%) situou-se na subcategoria "Desenvolvimento Biopsicossocial". Nesse caso, fica estabelecido que, para os professores, a dimensão afetiva é uma questão inerente ao comportamento sexual humano, uma vez que está relacionada aos seus sentimentos e ações em nível individual e pessoal, como também argumentaram outros autores. (LAMEIRAS et al., 2016; DAMASIO, 2018). Por outro lado, os demais professores registraram concepções orientadas a subcategorias que se distanciam dessa postura, ignorando o componente social e/ou coletivo da sexualidade, ou considerando que a afetividade é uma questão que deve ser abordada de forma independente e com o apoio de campos especializados como psicologia (veja a Figura 2).

Figura 2: Frequências da Categoria de Dimensão Afetiva

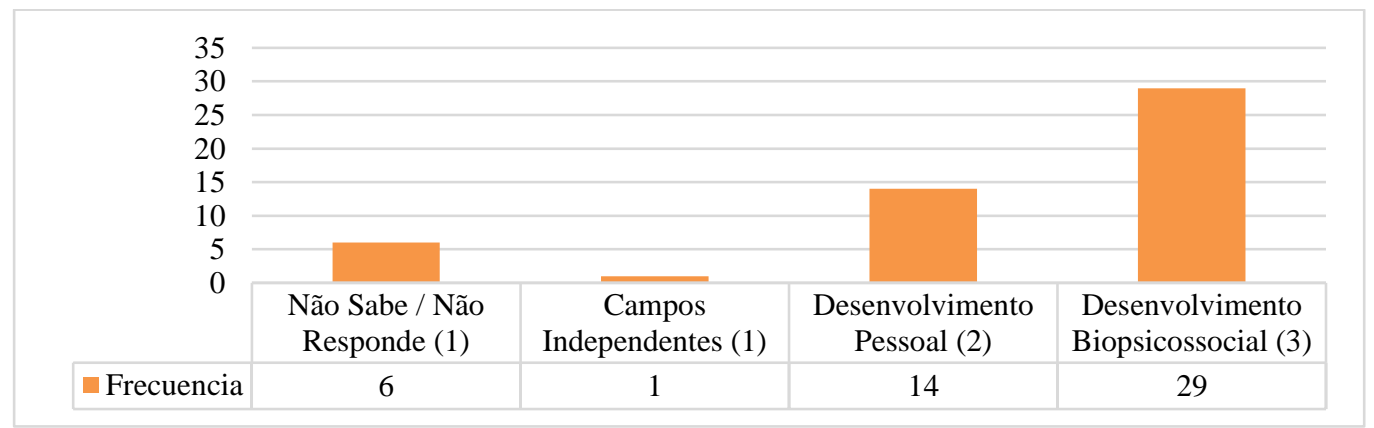

Fonte: Autores 
DOI: http://doi.org/10.46667/renbio.v14i1.553

A seguir, são apresentadas algumas evidências textuais das respostas dos professores em formação à questão desta categoria.

DF8.C1.P7 [Referindo-se a Afetividade e Sexualidade como Campos Independentes] "Não, isso é muito separado, porque esses sentimentos são muito pessoais".

DF19.C1.P7 [Referindo-se a Afetividade e Sexualidade como Desenvolvimento Pessoal] "Sim, porque as emoções e os sentimentos fazem parte do desenvolvimento sexual do ser humano, portanto, devem ser incluídos na educação sexual".

DF33.C1.P7 [Referindo-se a Afetividade e Sexualidade como Desenvolvimento Biopsicossocial] "Sim, porque do lado neural podemos trocar diferentes tipos de reações químicas que secretam não só serotonina, mas também, querendo descobrir cada vez mais, quão incrível é a sexualidade através da ciência e vida".

Do exposto, fica evidente que, para esses professores em formação, a sexualidade extrapola as posições biológicas e está ligada a emoções e sentimentos, que dependem da identidade de cada pessoa e de suas relações interpessoais. Esses resultados contrastam com outros estudos que mostram como um grupo de professores de um curso de Ciências Biológicas no Brasil, apresenta concepções e atitudes que os levam a propor estratégias de sala de aula em Educação Sexual, que excluem debates sobre temas como gênero, diversidade sexual e afetividade humana (FIGUEIREDO; SOUZA, 2016).

Por outro lado, embora estes resultados sejam encorajadores, ainda são contraditórios com os resultados analisados na primeira secção desta secção, pelo que é necessário insistir na relevância de ligar a afetividade e a exploração das emoções aos cenários de formação de emoções, professores de ciências, não apenas como estratégia de sua prática docente no tratamento de temas como a sexualidade, mas como uma questão de desenvolvimento profissional. A este respeito, argumentou-se que a gestão adequada das emoções pode não só melhorar a formação inicial do professor, mas também promover a aprendizagem ao longo da vida e melhorar o desempenho profissional futuro (NALIPAY et al., 2019). Da mesma forma, e nesta mesma perspectiva, sabe-se que o estudo das emoções na formação inicial de professores, fornece elementos educativos para o seu desempenho futuro na mediação da aprendizagem dos seus alunos (RETANA et al., 2018). Apesar disso, porém, o corpo de pesquisas sobre as emoções de professores de ciências ativos e estagiários está crescendo (ClARKE, 2013; KELLER et al., 2014; TAXER; FRENZEL, 2015; FRIED et al., 2015; VOLET et al., 2019; CHEN, 2019), dão pouca ênfase ao processo de ensino e aprendizagem de ciências e sua relação com a dimensão afetiva durante a formação inicial de professores.

Sobe o anterior, Plaza (2015) considera que, quando temas relacionados à Saúde Sexual e Reprodutiva são abordados nas aulas de ciências, os professores colocam em jogo suas crenças pessoais e coletivas sobre sexualidade e gênero. Assim, o não reconhecimento dessas 
DOI: http://doi.org/10.46667/renbio.v14i1.553

crenças pode perpetuar posições estereotipadas sobre a sexualidade e definidas por diretrizes heteronormativas sobre masculinidades e feminilidades (ARESKOUG-JOSEFSSON et al., 2013). Além disso, esse reconhecimento permite que os próprios professores reflitam sobre sua própria experiência de vida, evitando a replicação de vieses conceituais e crenças socioculturais que afetam o desenvolvimento das práticas afetivo-sexuais de seus alunos. Todos esses argumentos tornam mais uma vez relevante investigar a dimensão afetiva dos próprios professores no quadro do ensino e aprendizagem da sexualidade (BURIĆ et al., 2018).

3.3 O que os professores em formação pensam sobre as questões da diversidade sexual na sala de aula de ciências

Nesta categoria, os professores em formação foram questionados sobre a possibilidade de vincular questões relacionadas à diversidade sexual nas aulas de ciências naturais. Assim, 15 dos professores (30\%) situaram-se na subcategoria "Formação Humana Integral", demonstrando que a educação sexual deve promover não só o reconhecimento do próprio corpo e dos direitos pessoais, mas também promover o respeito ao outro como sujeito com direitos e deveres. Para este grupo maioritário da população participante é importante reconhecer a diversidade e respeitá-la, valorizando as diferentes expressões comportamentais e construindo pontes de comunicação assertiva e tolerante na sociedade. Da mesma forma, as subcategorias do pensamento reducionista como "Informações Gerais" e "Reprodução Biológica" se destacam na Figura 3.

Figura 3: Frequências da Categoria Diversidade Sexual

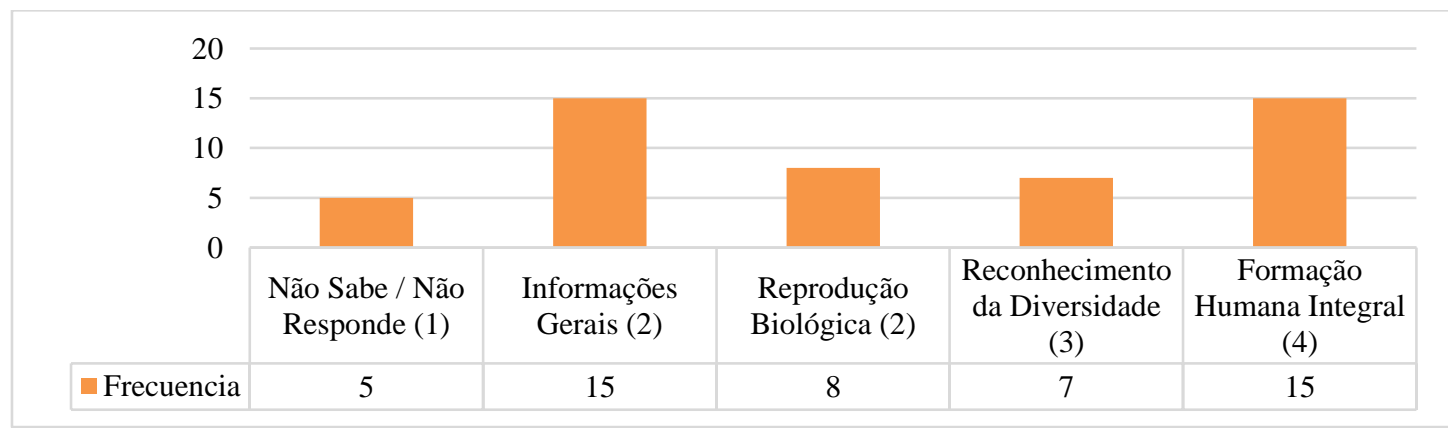

Fonte: Autores

A seguir, são apresentadas algumas evidências textuais das respostas dos professores em formação à questão desta categoria.

DF14.C1.P9 [Referindo-se à inclusão da Diversidade Sexual na aula de Ciências como Reprodução Biológica] "na medida em que se fala, por exemplo, de genética, que é uma forma de conceber essa diversidade sexual".

DF37.C1.P9 [Referindo-se à inclusão da Diversidade Sexual na aula de Ciências como Reconhecimento] "Se a diversidade sexual se refere à orientação (LGTBI) é um tanto difícil dizer que teria um espaço nas salas de aula, porque estamos em um país e muito educação conservadora". 
DOI: http://doi.org/10.46667/renbio.v14i1.553

DF40.C1.P9 [Referindo-se à inclusão da Diversidade Sexual na sala de aula de Ciências como Formação Humana e Integral] "Em grande medida, pois é importante que os jovens sejam capazes de reconhecer sua identidade sexual e não se sintam reprimidos ou violados por preconceitos e rótulos que eles impor, eles podem ser evitados se você tiver uma educação sexual adequada".

Esses resultados permitem considerar que, para professores em formação, é importante reconhecer a diversidade sexual e pensar em como essas questões se tornam uma contribuição para a construção da cultura cívica. Para eles, é importante superar as posições científicas que abordam a homossexualidade, intersex ou transexualidade como questão limitada aos cromossomos ou herança genética (GONZÁLEZ et al., 2015; OROZCO, 2018). Pelo contrário, propõem principalmente que a diversidade é uma questão cultural que enriquece a espécie humana e que este processo deve ser aprendido para formar as novas gerações de forma integral. Esses achados estão relacionados aos de Biancon et al., (2017), em estudo sobre o ensino de sexualidade e questões de gênero em escolas públicas do Paraná (Brasil), que identifica a necessidade de superação dos conflitos presentes nas escolas sobre as questões relacionadas à diversidade sexual e à construção de gênero. Além disso, para esses autores, a prática docente é um referencial essencial para a realização desse objetivo.

Apesar desses resultados, outros também podem ser observados, os quais mostram que existe um número considerável de professores em formação que consideram a diversidade sexual um tema de interesse informativo ou de competência ímpar à genética humana. Esse resultado concorda com outros que argumentam que o conhecimento dos professores sobre a sexualidade e sua diversidade é precário, e suas crenças errôneas contribuem para a manutenção dos preconceitos prevalecentes na sociedade (BORTOLOZZI; VILAÇ, 2017). Da mesma forma, esses resultados referem-se à necessidade de ter espaços de discussão e propostas curriculares alternativas em torno das questões da sexualidade humana nos cenários de formação inicial de professores de ciências, articulando temas como inclusão educacional, Educação em Saúde e reconhecimento da diversidade cultural (MOSQUERA; AMÓRTEGUI, 2018; Löfgren-MÅRTENSON; OUIS, 2019). Esses espaços curriculares proporcionarão oportunidades de questionamento de estereótipos pessoais e culturais, e que promovam a formação inclusiva de uma Dimensão Afetivo-Sexual.

\subsection{Objetivos de Ensino para Educação Sexual propostos por professores em formação em} ciências

Quando os professores em formação foram questionados sobre possíveis objetivos de ensino para o tema sexualidade a partir do ensino de ciências, para 24 deles (48\%) é importante que o ensino de ciências não contribua apenas para a compreensão de questões teóricas e científicas ligadas à sexualidade antes, é necessário buscar uma "Formação Integral e Cultural”, que ofereça experiências educacionais relevantes para a vida a partir da análise de contextos. $\mathrm{Na}$ mesma linha, outros grupos de professores acreditam que os propósitos da inclusão da educação sexual no ensino de ciências estão relacionados a reconhecer o outro em sua 
DOI: http://doi.org/10.46667/renbio.v14i1.553

diversidade e melhorar a atitude dos alunos em relação a essas questões. Por outro lado, para um grupo significativo de 8 professores o ensino da sexualidade deveria se limitar a aproximar os alunos do "Conhecimento Científico" sobre sexualidade, e nesta mesma linha para outro grupo igualmente significativo de professores ( 20 deles) deveria ser aprenda sobre sexualidade para levar uma vida sexual de controle e cuidado.

A seguir, são apresentadas algumas evidências textuais das respostas do corpo docente em treinamento à questão desta categoria.

DF41.C1.P10 [Referindo-se aos Objetivos de Ensino como Promoção e Prevenção] "Por fim, levaria em consideração as alternativas de métodos contraceptivos, em que os alunos tomem conhecimento de que o uso do preservativo é muito importante para evitar qualquer tipo de doença ou precocemente idade gestacional, também que tenham consciência de valorizar e respeitar seu corpo".

DF36.C1.P10 [Referindo-se aos Objetivos de Ensino como Diversidade de Inclusão] "Um dos principais objetivos seria abrir os olhos das crianças para modelos errôneos de sexualidade. Mostrar que o mundo é diverso e que há espaço para todos e que essa diversidade está imersa tanto na natureza humana, animal e vegetal, quanto no conhecimento sobre práticas sexuais seguras e saudáveis em crianças e jovens”.

DF34.C1.P10 [Referindo-se aos Objetivos de Ensino como Formação Integral] "Fornecer bases para que crianças e adolescentes conheçam seu corpo e as diferenças que existem no mundo e, assim, possam ter um conhecimento claro e confiável sobre o assunto".

Em primeiro lugar, é importante ter em mente que as finalidades do ensino da sexualidade a partir da educação em ciências propostas pelos professores em formação estão relacionadas às suas experiências emocionais e de aprendizagem anteriores, tanto como alunos do ensino fundamental ou médio, como na mesmos programas de graduação. Assim, os professores em formação parecem ter recebido uma formação que os capacita a pensar que a inserção da sexualidade na educação científica faz parte da formação integral dos sujeitos e permite a adoção de competências e valores de cidadania sobre a temática. Da mesma forma, esses resultados podem ser devidos ao fato de eles poderem pensar que o tema sexualidade gera emoções positivas nos alunos por ter valor em seu cotidiano (captar, compreender e regular as emoções, alcançar o equilíbrio) como afirmam outros autores (EXTREMERA et al., 2019; HENAO; MARIN, 2019), promovendo assim o seu interesse, confiança e participação nas atividades, conforme consta de outros estudos (WU; CHEN, 2018; YUAN: LEE, 2019) e, assim, o melhor entendimento de os conceitos associados a ele. A respeito disso, é importante dizer que a Educação Sexual como questão transversal tem se posicionado nos professores a partir de programas de formação inicial (LINDGREN, 2019).

Figura 4: Frequências da Categoria Objetivos de Ensino 
DOI: $h$ htp://doi.org/10.46667/renbio.v14i1.553

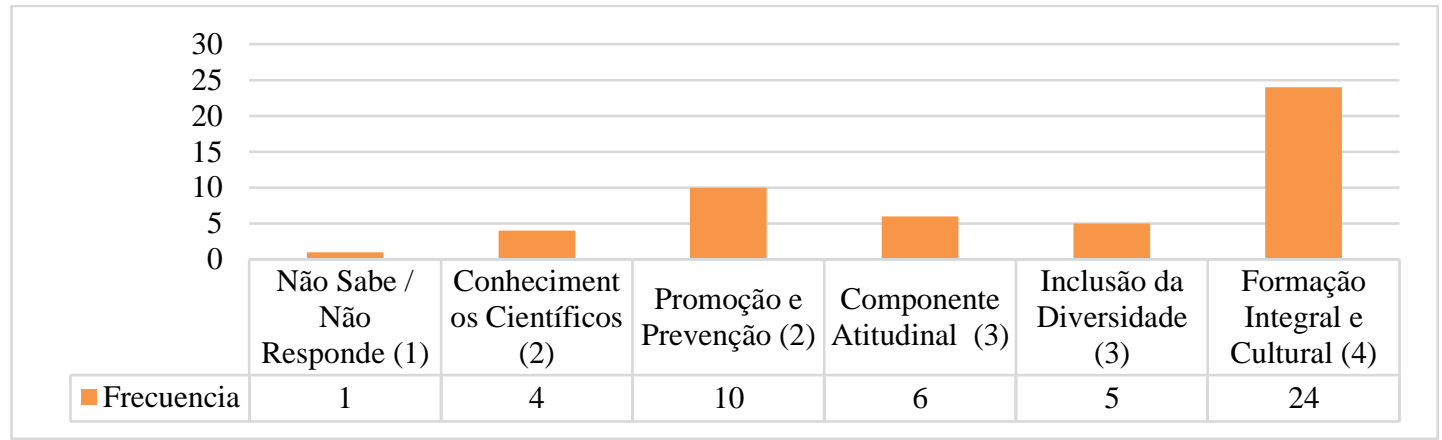

Fonte: Autores

Nessa mesma perspectiva, reconhece-se que as propostas em Educação Afetiva-Sexual com professores contribuem significativamente para a mobilização de concepções e atitudes frente às questões temáticas dessa dimensão da Educação em Saúde (EPS). Autores como Porter et al., (2019) reconhecem que, após uma intervenção de formação afetivo-sexual com professores em cenários de formação inicial, contribui para o aprimoramento do conhecimento, para a mobilização de concepções e para o desenho de propostas de aula reflexivas coerentes com o contexto e suas necessidades (TALAVERA et al., 2018). Então, uma proposta em Educação Afetivo-Sexual contribui para a aprendizagem dos próprios professores e para suas futuras práticas educacionais que deverão desenvolver, influenciando as ações de seus alunos (HIGHAM, 2018; LINDGREN, 2019).

Mas, por outro lado, como interpretar os resultados que expressam como dois grupos significativos de professores em formação acreditam que a inclusão da sexualidade no ensino de ciências deve ser feita de forma a aproximar os alunos do Conhecimento Científico sobre a sexualidade, e conduzir uma sexualidade vida de controle e cuidado, concepções que correspondem a um modelo médico biológico de educação sexual? A este respeito, autores como Lameiras et al., (2013; 2016) estabelecem que, para a maioria dos professores de ciências, os obstáculos à implementação de uma Educação Sexual rigorosa e sistemática na escola podem estar associados à falta de formação inicial, a dificuldades de acesso a cenários de formação contínua e falta de recursos e tempo devido à sua situação laboral; situação de emprego que em contextos ibero-americanos não é muito otimista.

\section{Considerações finais}

Este estudo mostrou, em primeiro lugar, que para esses professores de ciências, a articulação da sexualidade ao ensino de ciências pode se limitar a modelos de educação clínica preventiva. Visto que, ao questionar a definição de sexualidade e ao indagar sobre questões como a diversidade sexual, uma boa porcentagem do corpo docente em formação limita-se ao conteúdo biológico. Então, sob essa ótica do processo educativo, não importaria a formação afetiva e cultural do aluno, pois, nas palavras de muitos dos professores, a ciência deve responder a questões relacionadas à genética, à reprodução humana e à recepção de estímulos., 
DOI: http://doi.org/10.46667/renbio.v14i1.553

afastando-se de questões como comportamento, identidade de gênero e reconhecimento afetivosexual daqueles que não são determinados por diretrizes heteronormativas.

Por outro lado, este estudo também possibilitou reconhecer o interesse dos professores pela formação em educação sexual, compreendendo a relevância de avaliar seu componente afetivo nas práticas de formação, como vincular afetos, sentimentos e emoções ao desenvolvimento da sexualidade. Sexualidade humana. Isso é relevante, pois fica evidenciada a necessidade da Educação Afetivo-Sexual que, além de cumprir as diretrizes ministeriais na Colômbia, promove a formação crítica e contextualizada dos cidadãos. Por esses motivos, a formação inicial e permanente de professores deve incluir esse tema em suas propostas. Além disso, não é de menor importância reconhecer que a implementação de estratégias apropriadas nas futuras gerações de professores contribuirá para melhorar a formação em sexualidade de meninos, meninas e jovens que frequentarão as aulas de ciências desses futuros professores, e do a experiência coletiva vai construir sua saúde afetivo-sexual.

\section{Referências}

AGUD, D.; GUIJARRO, I.; GIL, M.D.; GAVIDIA, V. La educación afectivo-sexual en la educación obligatoria. Estudio de las propuestas curriculares del Ministerio y de la Comunidad Valenciana. In: GAVIDIA, Valentin (Coord.). Los ocho ámbitos de la Educación para la Salud en la Escuela. Valencia: Tirant Humanidades, 2016. p. 227-243.

ALIAGA, P.; BUENO, M.; FERRER, E.; GÁLLEGO, J.; RAMÓN, J.; MORENO, C.; MUÑOZ, P.; PLUMED, M.; VILCHES, B. Las escuelas promotoras de salud, un entorno para desarrollar competencias y vivir experiencias positivas para la salud: la experiencia de Aragón. In: GAVIDIA, Valentin (Coord.), Los ocho ámbitos de la educación para la salud en la escuela. Valencia: Tirant Humanidades, 2016, p. 45-66.

AMÓRTEGUI, E.; MOSQUERA, J. Aportaciones de la práctica pedagógica en la construcción del conocimiento del profesor. Tecné, Episteme \& Didaxis - TED, Bogotá, v. 43, n. 1, jan. /jun., p. 47-65, 2018. Disponível em: https://revistas.pedagogica.edu.co/index.php/TED/article/view/8651/6518. Acesso em: $20 \mathrm{de}$ jul. 2020.

ARESKOUG-JOSEFSSON, K.; CHUCHU, A.; DEOGAN, Ch.; LINDROTH, M. Education for sexual and reproductive health and rights (SRHR): a mapping of SRHR-related content in higher education in health care, police, law and social work in Sweden. Sex Education, v. 19, n. 6, p. 720-729, 2019. Disponível em: https://www.tandfonline.com/doi/full/10.1080/14681811.2019.1572501 . Acesso em: 20 de fev. 2020.

BARDÍN, L. Analyse de contenu. Paris: Presses Universitaries de France, 1977. 
DOI: http://doi.org/10.46667/renbio.v14i1.553

BIANCON, M.L.; ROSAS, C.; OLIVO, A.L. Educação em sexualidades crítica nas escolas do campo: investigação da prática social das/os professoras/es. In: PEIXOTO, A.;

OLIVEIRA, J.; GONÇALVES, J.; NEVES, L.; CRUZ, R. (Ed.). Educação em ciências em múltiplos contextos - ENCONTRO NACIONAL DE EDUCAÇÃO EM CIÊNCIAS - ENEC, 17., 2017; I SEMINÁRIO INTERNACIONAL DE EDUCAÇÃ̃O EM CIÊNCIAS - SIEC, 1 ., 2017. Atas do... Vina do Castelo: Instituto Politécnico de Viana do Castelo, Escola Superior de Educação, 2017, p. 471-478.

BORRACHERO, A.B. Las emociones en la enseñanza y el aprendizaje de las ciencias en educación secundaria. 2015. Tese (Doutorado em Didáctica de las Ciencias Experimentales y Matemáticas). Extremadura, España: Universidad de Extremadura, 2015.

BORTOLOZZI, A.C.; VILAÇA, T. (2017). Conhecimento de professores/as sobre sexualidade e deficiencias. In: PEIXOTO, A.; OLIVEIRA, J.; GONÇALVES, J.; NEVES, L.; CRUZ, R. (Ed.). Educação em ciências em múltiplos contextos - ENCONTRO NACIONAL DE EDUCAÇÃO EM CIÊNCIAS - ENEC, 17., 2017; I SEMINÁRIO INTERNACIONAL DE EDUCAÇÃO EM CIÊNCIAS - SIEC, 1., 2017. Atas do... Vina do Castelo: Instituto Politécnico de Viana do Castelo, Escola Superior de Educação, 2017, p. 428-436.

BURIĆ, I.; SLIŠKOVIĆ, A.; MACUKA, I. A mixed-method approach to the assessment of teachers' emotions: development and validation of the Teacher Emotion Questionnaire.

Educational Psychology, v. 38, n. 3, p. 325-349, 2018. Disponível em: https://www.tandfonline.com/doi/abs/10.1080/01443410.2017.1382682 . Acesso em: 20 de fev. 2020.

CEDEÑO, K.; BARRERO, F.E.; MOSQUERA, J.A. Educación sexual y para la salud, una propuesta desde la perspectiva biopsicosocial en Neiva, Huila. Bio-grafía: Escritos sobre la Biología y su Enseñanza, Número Extraordinario, p. 1433-1442, 2017. Disponível em: https://revistas.pedagogica.edu.co/index.php/bio-grafia/article/view/7318/5974. Acesso em: 10 de dez. 2020.

CHEN, J. Efficacious and positive teachers achieve more: examining the relationship between teacher efficacy, emotions, and their practicum performance. Asia-Pacific Education Research, v. 28, n. 4, p. 327-337, 2019. Disponível em: https://link.springer.com/article/10.1007/s40299-018-0427-9. Acesso em: $10 \mathrm{de} \mathrm{dez.} 2020$.

CLARKE, K. Pedagogical moments: affective sexual literacies in film. Sex Education, v. 13, n. 3, p. 263-275, 2013. Disponível em:

https://www.tandfonline.com/doi/abs/10.1080/14681811.2012.718992. Acesso em: 10 de dez. 2020.

DAMASIO, A. En busca de Spinoza. Barcelona: Crítica S.L., 2003.

DAMASIO, A. El extraño orden de las cosas. Bogotá: Editorial Planeta Colombia, 2018. 
DOI: http://doi.org/10.46667/renbio.v14i1.553

EXTREMERA, N.; MÉRIDA-LÓPEZ, S.; SÁNCHEZ-ÁLVAREZ, N.; QUINTANA-ORTS, C.; REY, L. Un amigo es un tesoro: inteligencia emocional, apoyo social organizacional y engagement docente. Praxis \& Saber, v. 10, n. 24, p. 69-92, 2019. Disponível em:

https://revistas.uptc.edu.co/index.php/praxis_saber/article/view/10003. Acesso em: $10 \mathrm{de}$ dez. 2020.

FALLAS, M.A. Educación afectiva y sexual, programa de formación docente de secundaria. 2009. Tese (Doutorado). Universidad de Salamanca, Salamanca, España, 2009.

FIGUEIREDO, R.; SOUZA, M. Gênero e Sexualidade: diálogos na formação de licenciandos/as em Ciências Biológicas. Revista Tecné, Episteme y Didaxis: TED, Número Extraordinario, p. 1762-1767, 2016. Disponível em:

https://revistas.pedagogica.edu.co/index.php/TED/article/view/4811. Acesso em: 20 de dez. 2019.

FOUCAULT, M. Historia de la Sexualidad 3 - La inquietud de sí. Buenos Aires: Siglo XXI Editores Argentina S.A., 2003.

FRIED, L.; MANSFIELD, C.; DOBOZY, E. Teacher emotion research: Introducing a conceptual model to guide future research. Issues in Educational Research, v. 25, n. 4, p. 415-441, 2015. Disponível em: https://core.ac.uk/reader/81695270. Acesso em: 20 de dez. 2019.

GARCÍA-VÁZQUEZ, J.; LENA, A.; SUÁREZ, O. Evaluación de proceso del programa de educación afectivo-sexual Ni ogros ni princesas. Global Health Promotion, v. 19, n. 7, 2012. Disponível em: https://journals.sagepub.com/doi/10.1177/1757975912441224. Acesso em: 20 de dez. 2019.

GARCÍA, J.J. ¿Para qué educar? Uni-pluri/versidad, Medellín, v. 18, n. 1, p. 11-12, 2018. Disponível em: https://revistas.udea.edu.co/index.php/unip/article/view/335809. Acesso em: 20 de fev. 2020.

GARCÍA, J.J. Ciencia consentida: resignificando los sentidos en la enseñanza de la ciencia. Tecné, Episteme \& Didaxis - TED, Bogotá, v. 47, n. 1, p. 217-231, 2020. Disponível em: https://revistas.pedagogica.edu.co/index.php/TED/article/view/11337/8096 . Acesso em: 20 de nov. 2020.

GAVIDIA, V. Los ocho ámbitos de la educación para la salud en la escuela. Valencia: Tirant Humanidades, 2016.

GONZALEZ, E.; MOLINA, T.; LUTTGES, C. Características de la educación sexual escolar recibida y su asociación con la edad de inicio sexual y uso de anticonceptivos en adolescentes chilenas sexualmente activas. Revista Chilena de Obstetricia y Ginecología, v. 80, n. 1, p. 24-32, 2015. Disponível em:

https://scielo.conicyt.cl/scielo.php?script=sci_arttext\&pid=S0717-75262015000100004.

Acesso em: 20 de nov. 2019. 
DOI: http://doi.org/10.46667/renbio.v14i1.553

HENAO, J.F.; MARÍN, A.E. El proceso de enseñanza desde el prisma de las emociones de los docentes. Praxis \& Saber, v. 10, n. 24, p. 193-215, 2019. Disponível em: https://revistas.uptc.edu.co/index.php/praxis_saber/article/view/9415. Acesso em: 20 de fev. 2019.

HIGHAM, L. An affective politics of sexual harassment at school in the 21st century: Schooling and Sexualities twenty years later. Sex Education, v. 18, n. 3, p. 293-306, 2018. Disponível em: https://www.tandfonline.com/doi/abs/10.1080/14681811.2018.1431879. Acesso em: 20 de nov. 2019.

KELLER, M. M.; CHANG, M. L.; BECKER, E. S.; GOETZ, T.; FRENZEL, A. C. Teachers' emotional experiences and exhaustion as predictors of emotional labor in the classroom: An experience sampling study. Frontiers in Psychology, v. 5, p. 376-407, 2014. Disponível em: https://www.frontiersin.org/articles/10.3389/fpsyg.2014.01442/full. Acesso em: 20 de nov. 2019.

LAMEIRAS, M.; CARRERA, M.V.; RODRÍGUEZ, Y. Sexualidad y Salud: El estudio de la sexualidad humana desde una perspectiva de género. Vigo: Servicio de Publicaciones. Universidad de Vigo, 2013.

LAMEIRAS, M.; CARRERA, M.V.; RODRÍGUEZ, Y. Caso abierto: la educación sexual en España una asignatura pendiente. In: GAVIDIA, Valentin (Coord.), Los ocho ámbitos de la Educación para la Salud en la Escuela. Valencia: Tirant Humanidades, 2016, p. 197-210.

LENOIR, F. El milagro Spinoza. Bogotá: Editorial Planeta Colombia S.A., 2019.

LEÓN-RUBIO, J.M.; LEÓN-PÉREZ, J.M.; CANTERO, F.J. Prevalencia y factores predictivos del burnout en docentes de la enseñanza pública: el papel del género. Ansiedad y Estrés, v. 19, n. 1, p. 11-25, 2013. Disponível em: https://psycnet.apa.org/record/2013-18332002. Acesso em: 20 de nov. 2019.

LINDGREN, A-L. Towards an ethics of sexuality - alternative feminist figurations and a (boy) child: a close reading of a prize-winning sex education manual from the early twentieth century. Gender and Education, v. 31, n. 6, p. 774-787, 2019. Disponível em: https://www.tandfonline.com/doi/full/10.1080/09540253.2018.1440282. Acesso em: 20 de fev. 2020.

LÖFGREN-MÅRTENSON, Ch.; OUIS, P. We need “culture-bridges": professionals' experiences of sex education for pupils with intellectual disabilities in a multicultural society. Sex Education, v. 19, n. 1, p. 54-67, 2019. Disponível em: https://www.tandfonline.com/doi/full/10.1080/14681811.2018.1478806. Acesso em: 20 de fev. 2020.

MARINA, J.A. El rompecabezas de la sexualidad. Barcelona: Editorial Anagrama, 2002. 
DOI: http://doi.org/10.46667/renbio.v14i1.553

MORAWICKI, P.; RAMOS, R.; MEINARDI, E. Prácticas de enseñanza en educación para la salud en egresados del profesorado en biología de la UNaM. Revista Ciencia y Tecnología, n.16, p. 5-12, 2011. Disponível em:

https://www.fceqyn.unam.edu.ar/recyt/index.php/recyt/article/view/481/402. Acesso em: 20 de nov. 2019.

MOSQUERA, J.; GARCÍA, J. (2020). Estado do arte da dimensão afetivo-sexual na formação de professores de ciências. In: ANASTÁCIO, Z.; BATTISTI, I.; CARVALHO, G. S. (Org.) $7^{\circ}$ CONGRESSO INTERNACIONAL EM SAÚDE, CISAÚDE-2020, CONTEXTOS E PROBLEMÁTICAS EMERGENTES, 7., 2021. Anais do... Braga, Portugal: Centro de Investigação em Estudos da Criança (CIEC); Instituto de Educação, Universidade do Minho, 2020, p. 69-70.

MOSQUERA, J.; AMÓRTEGUI, E. Inserción docente del profesorado principiante de ciencias naturales en el sur de Colombia. Tecné, Episteme \& Didaxis - TED, Número Extraordinario, 2018. Disponível em:

https://revistas.pedagogica.edu.co/index.php/TED/article/view/8748/6580. Acesso em: 20 de nov. 2019.

NALIPAY, M.J.; MORDENO, I.; SEMILLA, J.B.; FRONDOZO, Ch. Implicit beliefs about teaching ability, teacher emotions, and teaching satisfaction. Asia-Pacific Education Research, v. 28, n. 4, p. 313-325, 2019. Disponível em: https://link.springer.com/article/10.1007/s40299-019-00467-z. Acesso em: 20 de fev. 2020.

OCAMPO, D.C.; PEÑARANDA F.; ALZATE-YEPES, T.; GÓMEZ, M.M.; CARRILLO, M.; VALENCIA, A. Sentidos construidos frente a la educación para la salud en estudiantes, docentes y egresados de programas de educación superior del área de la salud. Perspectivas en Nutrición Humana, v. 18, n. 1, p. 49-60, 2016. Disponível em: https://revistas.udea.edu.co/index.php/nutricion/article/view/27100/20791193. Acesso em: 20 de nov. 2019.

OROZCO, Y. Las experiencias de vida de personas transgénero y transexuales: Diálogos posibles con la enseñanza de las ciencias naturales. Tecné, Episteme y Didaxis - TED, Número Extraordinário, 2018. Disponível em:

https://revistas.pedagogica.edu.co/index.php/TED/article/view/9150. Acesso em: 20 de nov. 2019.

PLAZA, M.V. Caracterización de las creencias sobre sexualidad de los profesores y su incidencia en las prácticas sobre educación sexual en la escuela media. 2015. Tese (Doutorado) - Universidad de Buenos Aires. Buenos Aires, Argentina, 2015.

PORTER, A.; COOPER, S.; HENRY, M.; GALLO, J.; GRAEFE, B. The nature of peer sexual health communication among college students enrolled in a human sexuality course. American Journal of Sexuality Education, v. 14, n. 2, p. 139-151, 2019. Disponível em: https://www.tandfonline.com/doi/abs/10.1080/15546128.2018.1529644? journalCode=wajs2. Acesso em: 20 de nov. 2019. 
DOI: http://doi.org/10.46667/renbio.v14i1.553

RETANA-ALVARADO, D.A.; CAMACHO, M.M.; OSBORNE, A.; VÁZQUEZ-BERNAL, B.; JIMÉNEZ-PÉREZ, R.; DE LAS HERAS, M.A. Emociones de estudiantes costarricenses de secundaria respecto al desarrollo de un proyecto de indagación según el género. In: MARTÍNEZ, C.; GARCÍA, S. (Ed.) 280 Encuentros de Didáctica de las Ciencias Experimentales. Iluminando el cambio educativo. Universidade da Coruña: Servizo de Publicacións, 2018, p. 1289-1294.

SORDO, P. Educar para sentir, sentir para educar. Santiago de Chile: Editorial Planeta Chilena S.A., 2017.

TALAVERA, M.; MAYORAL, O.; HURTADO, A.; MARTÍN-BAENA, D. Motivación docente y actitud hacia las ciencias: influencia de las emociones y factores de género. Revista Electrónica de Enseñanza de las Ciencias, v. 17, n. 2, p. 461-475, 2018. Disponível em: http://reec.uvigo.es/volumenes/volumen17/REEC_17_2_09_ex1349.pdf. Acesso em: 20 de nov. 2019.

TAXER, J. L.; FRENZEL, A. Facets of teachers' emotional lives: a quantitative investigation of teachers' genuine, faked, and hidden emotions. Teaching and Teacher Education, v. 49, p. 78-88, 2015. Disponível em:

https://www.sciencedirect.com/science/article/abs/pii/S0742051X15000438. Acesso em: 20 de nov. 2020.

VOLET, S.; SEGHEZZI, C.; RITCHIE, S. Positive emotions in student-led collaborative science activities: relating types and sources of emotions to engagement in learning. Studies in Higher Education, v. 44, n. 10, p. 1734-1746, 2019. Disponível em: https://www.tandfonline.com/doi/abs/10.1080/03075079.2019.1665314? journalCode=cshe20. Acesso em: 20 de nov. 2020.

WU, Z.; CHEN, J. Teachers' emotional experience: insights from Hong Kong primary schools. Asia Pacific Education Review, v. 19, n.4, p. 531-541, 2018. Disponível em: https://eric.ed.gov/?id=EJ1198381. Acesso em: 20 de nov. 2020.

YUAN, R.; LEE, I. 'I need to be strong and competent': a narrative inquiry of a studentteacher's emotions and identities in teaching practicum. Teachers and Teaching, v. 22, n. 7, p. 819-841, 2016. Disponível em: https://www.tandfonline.com/doi/abs/10.1080/13540602.2016.1185819. Acesso em: 20 de nov. 2020.

Recebido em março de 2021.

Aprovado em abril de 2021.

Revisão gramatical realizada por: Jonathan Andrés Mosquera

E-mail: jonathan.mosquera@usco.edu.co 